\title{
A práxis da educação popular: considerações sobre sua história e seus desafios diante da consolidação do campo das práticas socioeducativas
}

\author{
Luís Antonio Groppo', Suzana Costa Coutinho²
}

\begin{abstract}
Resumo
Por meio de revisão bibliográfica e reflexão acerca das atuais características da educação popular no Brasil, percebe-se sua importância histórica para a constituição do campo das práticas socioeducativas. Entretanto, seus princípios - diálogo, luta pela libertação e diversidade - são bastante subvertidos quando este campo se consolida. A recuperação da trajetória histórica da educação popular destaca suas origens nos tempos do populismo, sua vinculação aos movimentos sociais, sua participação na luta contra a ditadura e os desafios impostos desde o final do século XX. Tal recuperação da história e dos princípios da educação popular visa inspirar educadores e movimentos insatisfeitos com os atuais rumos do campo no qual se inserem, a fim de propor e viver heterodoxias criativas.
\end{abstract}

\section{Palavras-chave}

Educação Popular. Práxis. Práticas Socioeducativas. Pedagogia Social. Educação Não Formal.

1. Doutor em Ciências Sociais pela Universidade Estadual de Campinas, professor do Programa de Mestrado em Educação Sociocomunitária do Centro Universitário Salesiano de São Paulo (Unidade Americana), pesquisador do CNPq (Conselho Nacional de Pesquisa e Desenvolvimento Tecnológico). E-mail: luis.groppo@pq.cnpq.br.

2. Mestre em Educação Sociocomunitária pelo Centro Universitário Salesiano de São Paulo, professora da Fundação Educacional Dom José D'Angelo Neto, membro da ONG Centro Integrado de Apoio à Mulher de Pouso Alegre e Região (CIAMPAR). E-mail: suzana.coutinho@uol.com.br. 


\title{
The popular education and the field of socio-educative practices: considerations on the history of popular education and its current challenges
}

\author{
Luís Antonio Groppo*, Suzana Costa Coutinho**
}

\begin{abstract}
Through literature review and reflection on the current characteristics of popular education in Brazil, the historical importance of popular education is known for the formation of the field of socio-educative practices. However, the principles of popular education - dialogue, struggle for liberation and diversity - are quite subverted when this field is consolidated. The recovery of the historical trajectory of popular education emphasizes its origins in the time of populism, its relationship to social movements, its participation in the struggle against the dictatorship and the challenges imposed since the late twentieth century. This recovery of the history and principles of popular education movements aims to inspire educators dissatisfied with the current direction of the field where they belong, to live and to propose creative heterodoxies.
\end{abstract}

\section{Keywords}

Popular Education. Practice. Practice Social Educational. Social Education. Non Formal Education.

\footnotetext{
*Doctor in Social Sciences at the State University of Campinas, professor at the Master's Program in Social Communitarian Education at Salesiano University Centre of São Paulo (Unidade Americana), CNPq (Conselho Nacional de Pesquisa e Desenvolvimento Tecnológico) researcher. E-mail: luis.groppo@pq.cnpq.br.

** Master in Social Communitarian Education at Salesiano University Center of São Paulo, professor at Dom José D'Angelo Neto Educacional Foundation, ONG's member at Integrated Centre for Attention to Woman at Pouso Alegre and Region (CIAMPAR). E-mail: suzana.coutinho@uol.com.br.
} 


\section{Introdução}

A partir dos anos de 1990, no Brasil, tornou-se afamado o termo "educação não formal", desejando se referir a práticas educacionais que se distinguiam em seu modo de ser e objetivos em relação ao que seria a educação formal ou escolar. Mais recentemente, ganharam força renovada os termos "educação social" e "pedagogia social" que, na verdade, na qualidade de vocábulos, são bem antigos, mas adquiriram muitos sentidos ao longo da história e nos países onde foram evocados. Não seria surpresa um conflito entre os defensores de cada um dos rótulos, diante do atual processo de legitimação de um campo educacional que chamamos de "campo das práticas socioeducativas". Este conflito vem se dando e parece estar sendo vencido pela pedagogia social.

Qual seria a posição da educação popular neste debate e nesta constituição do campo das práticas socioeducativas? O objetivo deste artigo é colaborar com a reflexão sobre tal questão, por meio de uma análise fundada em pesquisa bibliográfica sobre educação popular e educação nos movimentos sociais. Busca, ainda, colaborar com a compreensão de um conceitochave para educação popular, qual seja, o de práxis. Além destes, um olhar panorâmico sobre a história da educação popular no Brasil e seus desafios contemporâneos.

\section{O campo das práticas socioeducativas e a educação popular}

Caracteriza o campo das práticas socioeducativas sua interseção entre o social e o educativo. Para seu nascimento, buscando distinguir-se da Educação Escolar e da Assistência Social, concorreram diversos atores, como o mercado social ${ }^{3}$, o Estado e as universidades.
Cada um deles contribuiu com recursos e discursos oferecidos para legitimar este campo das práticas socioeducativas e construir sua "ortodoxia", ou seja, seu próprio conjunto de ideias, valores e práticas tidos como legítimos.

Para a construção desta ortodoxia, a história recente e atual tem mostrado a grande importância do diálogo das universidades com aqueles que têm sido os principais dotadores de recursos econômicos e simbólicos para este campo: o Estado e o mercado social. Três foram os principais discursos e conjunto de práticas socioeducativas produzidas nesta história, refletindo em seu auge diferentes momentos da história de consolidação do campo das práticas socioeducativas: a educação popular, a educação não formal e a pedagogia social. O deslocamento do discurso proeminente foi diretamente influenciado pela sedimentação do mercado social e pelo incremento da participação do Estado no campo das práticas socioeducativas (tornandose seu principal legislador, gerente e provedor).

Primeiro, a educação popular. Seu ponto forte era o "social", ou seja, o objetivo de revolucionar as estruturas da sociedade, promotoras de injustiça e desigualdade. Quando o termo "pedagogia social" foi trazido para o Brasil, nas décadas de 1970 e 1980, teve grande influência dos valores da educação popular, como indica o clássico trabalho de Graciani (2001) sobre a pedagogia social de rua.

Em um segundo momento, ganhou força a proposta da educação não formal. Distintamente da popular, o ponto forte de seu ideário é o "educativo". Pesquisadores, que identificaram as diversas práticas de educação não formal no Brasil, destacaram as múltiplas intervenções educativas inventadas

3. Denominação usada pelos autores para se referir ao chamado "Terceiro Setor", composto pelas Organizações Não-Governamentais, fundações empresariais e outros. 
ou recriadas por educadores em locais distintos da escola, lidando com os mesmos educandos, oriundos das camadas populares da educação popular e da pedagogia social. A educação não formal apresentou uma proposta que enfatizava a metodologia educacional como seu diferencial. Com objetivos mais abertos e institucionalização "fraca", parecia haver espaço mais substancial para se cultivar uma amplitude de metas, objetivos e práticas, destacando-se as atividades esportivas, lúdicas e artísticas (GOHN, 2005; SIMSON; PARK; FERNANDES, 2001; PARK; FERNANDES, 2005).

Terceiro, a pedagogia social, que volta a fazer o "social" do "socioeducativo" ser o adjetivo proeminente (GARCIA, 2005). Contudo, é outra a sua concepção de "social": em vez de estruturas injustas a romper pela luta popular, o "social" aparece para a pedagogia social na forma da exclusão, situação de risco ou necessidade de cuidado. Os educandos são os excluídos (CALIMAN, 2010; GARRIDO; SILVA; EVANGELISTA, 2011; SILVA, 2010). A pedagogia social, apoiada pelo mercado social e orientada pelas políticas sociais do Estado, vem ganhando proeminência. Sua tendência é a promoção de outro tipo de institucionalização no campo das práticas socioeducativas, distinta da institucionalização escolar, pois que são outros os objetivos expressos. Se o objetivo declarado do campo escolar é a aprendizagem de saberes poderosos, no campo das práticas socioeducativas é a "inclusão social". A pedagogia social, reforçando o caminho da legitimação deste campo, pretende consolidar uma ciência própria para as práticas socioeducativas - a própria pedagogia social - que seria a base da formação, igualmente institucionalizada, dos educadores sociais, habilitados em cursos legitimados pela pedagogia social e orientados por esta ciência.

Contudo, o jogo ainda está em aberto. Na vida social, sempre está em aberto. Novos candidatos a formular outras concepções sobre as práticas socioeducativas podem aparecer. Para tanto, será imprescindível o conhecimento das tradições que fizeram a história deste campo, revivendo seus desejos e ideais, como a educação não formal e a educação popular, que ainda têm grande força e apelo e podem informar aqueles que se incomodam com os atuais contornos do campo das práticas socioeducativas ou discordam do papel que a educação popular foi relegada.

Neste sentido, retomar alguns dos conceitos centrais da educação popular pode ser de grande contribuição para este empenho. Iniciamos com o conceito de práxis.

\section{Educação popular como práxis}

O conceito de práxis, elaborado por Marx, compreende uma "ação transformadora" realizada pelo ser humano, pela qual ele transforma o mundo e também se transforma:

[...] o ser humano existe elaborando o novo, através da sua atividade vital, e com isso vai assumindo sempre, ele mesmo, novas características. (KONDER, 1992, p. 106).

É o trabalho, na visão de Marx, que torna o ser humano sujeito diante do objeto, e é essa capacidade de transformação (do mundo e de si mesmo) que faz a sua história. A partir dessa concepção, Freire afirma que

a desumanização é realidade histórica e negação de nossa vocação ontológica [...]. A superação desta condição é possibilidade histórica da qual se ocupa todo homem e toda mulher revolucionário(a). (FREIRE apud SCHNORR, 2005, p. 71).

Por isso, constrói-se uma práxis revolucionária que contém a educação como um elemento fundamental. Não se trata, no entanto, de qualquer forma de educação, mas de uma educação que se compromete com a 
libertação das pessoas que estão nela envolvidas, dos seus sujeitos educando-educadores. Para Freire (2009), trata-se de uma educação humanizadora, libertadora e crítica, que não existe sem conflitos, pois é seu papel também desmitificar a opressão que há mesmo dentro do oprimido, nas relações nas quais se identifica como "menos". O papel de tal práxis educativa é a realização do "ser mais", da humanização dos homens e mulheres envolvidos nessa práxis.

Chega-se ao conceito de práxis educativa popular, ou seja, a ação de "ensinar-eaprender" coletivamente com a finalidade de transformação libertadora de uma condição desumana. Ação e reflexão são componentes do que se chama práxis e, para Freire, tornamse uma palavra única, pois evidenciam uma reciprocidade e complementaridade. O sentido da práxis educativa popular está na intrínseca relação entre teoria e prática da educação, que se realiza a partir do diálogo entre os sujeitos envolvidos. É por meio das discussões que as visões de mundo se manifestam e podem ser questionadas, desmitificadas e, assim, abrir espaço para um novo conhecimento que leve a uma nova ação. Não se trata de um diálogo compreendido como mera "troca de palavras", mas de uma relação que se funda na capacidade de ouvir, questionar e de provocar a uma nova práxis, não imposta ou "repassada", mas construída por essa relação dialógica.

A práxis político-pedagógica de Freire tem como pressuposto o diálogo. Por isso, o autor se refere à ação como uma "concepção dialógica", ou ainda "educação dialógicodialética" (GADOTTI, 2000, p. 3). No entanto, talvez seja esta uma das categorias mais incompreendidas, tanto por críticos como por "seguidores" de Freire. Será importante para este trabalho a compreensão do diálogo freireano.

Em sua obra "Extensão ou comunicação?", Freire (1977) aponta como fundamental para uma prática educativa libertadora, dentro de uma perspectiva humanista ${ }^{4}$, o conceito de comunicação, contraposto ao de extensão, este no sentido de transferir, entregar, depositar. Para Freire, é a comunicação que possibilita aos sujeitos a coparticipação no ato de pensar, o que se dá por meio da reciprocidade, da intencionalidade e da não passividade. A comunicação é, pois, diálogo, "assim como o diálogo é comunicativo" (FREIRE, 2010, p. 67).

Neste sentido, diálogo pressupõe ouvir e falar. Saber escutar é um dos saberes necessários aos educadores, conforme a obra Pedagogia da Autonomia. Trata-se de uma ação crítica para poder intervir no diálogo, no falar com, e não apenas discursar para. No entanto, não deve o educador desconsiderar seu papel nessa relação dialógica, de intervenção também crítica que ajude a superar visões fatalistas, deterministas, opressoras. Não se trata de um ouvir e de um falar sem o compromisso com a libertação e com a humanização das pessoas. Pelo contrário, procurar ouvir e compreender quem diz a palavra, considerando também a linguagem, as imagens e os símbolos presentes, leva a, de forma criativa, se posicionar e mesmo discordar e se opor, mas nunca de forma autoritária, porque ouviu atentamente quem tinha a palavra. Um ouvir que se baseia também no acolhimento do outro, na tolerância e na disponibilidade à mudança, no respeito à diferença, pois não se coloca sobre o outro, entre tantas qualidades necessárias a quem quer dialogar (FREIRE, 2008, p. 119-120). Em Pedagogia do oprimido, Freire ressalta o caráter dialógico da prática educativa libertadora, adjetivando-a de problematizadora. Práxis que nega o depósito, a narrativa ou a transferência de conhecimento, para anunciar a "dialogicidade como essência da educação" (FREIRE, 2009, p. 78).

Freire (2009) chama sua práxis de

4. Para Freire, humanismo refere-se à humanização dos seres humanos, um "humanismo científico" que rejeita toda e qualquer forma de manipulação, pois que busca a libertação, esperançosamente crítico (FREIRE, 2010, p. 74.). 
educação problematizadora porque, por meio do diálogo, busca estimular a reflexão e a ação de homens e mulheres sobre a própria realidade. Diálogo que é palavra verdadeira, capaz de transformar porque também é capaz de pronunciar o mundo. Diálogo que é amor: o que impossibilita que se torne uma relação de dominação. Torna-se um ato de coragem e de compromisso com os homens e mulheres oprimidos. Compromisso que exige encontro dos sujeitos e encontro que exige compromisso para a realização da tarefa comum de libertarem-se e de transformarem sua realidade. Diálogo que renuncia a autossuficiência e exige a abertura ao outro, à sua contribuição. O que exige também a confiança dos sujeitos que dialogam, criando uma relação horizontal, o companheirismo; relação que, por sua vez, exige que as intencionalidades sejam ditas e que haja coerência entre o dizer e o fazer.

Outra exigência é a da esperança, pois sem ela fica vazio o encontro, tornando-o burocrático e fastidioso, pois se não se considera possível a mudança, porque se mobilizariam as pessoas, em que empenhariam suas forças e seus projetos? E ainda, exigência do diálogo, para Freire, também é o pensar crítico, reconhecendo a solidariedade entre "mundo-homens" e percebendo a realidade como processo, sendo possível e viável a "transformação permanente da realidade, para a permanente humanização dos homens" (FREIRE, 2009, p. 89-95).

\section{Educação popular: história e práxis}

A história da educação popular no Brasil e na América Latina, a partir do final da década de 1950, só poderá ser contada em complementaridade com a história dos movimentos populares.

Ainda, a filosofia, a pedagogia, a teologia, a economia, a arte e a literatura latinoamericana que nasciam dessa práxis libertadora apresentavam a marca de uma política criativa e apaixonada. Mostravam que os subalternos poderiam elaborar uma visão própria de mundo e colocar em marcha uma nova maneira de fazer política. A rigor, é possível dizer que os movimentos de libertação latino-americana são a versão tropical do que Gramsci havia delineado como filosofia da práxis, quer dizer, de uma filosofia que se faz política e de uma política que inspira a filosofia (SEMERARO, 2009, p. 100).

A década de 1950, no Brasil, é marcada pela aceleração do desenvolvimento econômico e da modernização, construída pela política desenvolvimentista. Esse período também foi, nos dizeres de Fávero (1983, p. 8),

[...] pródigo no transplante de experiências geradas em outro contexto: extensão rural, desenvolvimento de comunidades, educação de base, educação de adultos.

Essas expressões e ações anunciavam um determinado projeto político e de sociedade, ligado ao desenvolvimentismo e a uma ideia capitalista de democracia. Necessitava-se alfabetizar homens e mulheres para a disputa política regional e nacional e, também, para o trabalho nas indústrias. No entanto, na década de 1960, essas expressões tomaram novo sentido, contraditório ao primeiro uso. De forma crítica e criativa, buscou-se a construção de um projeto político em vista da superação da dominação do capital sobre o trabalho, debate presente nos diversos setores da sociedade brasileira, dos camponeses às universidades (STRECK, 2009).

Consideram-se, como pontos fundantes desse momento, no Brasil, segundo Brandão (1987): a gestação das ideias e práticas de Paulo Freire, asexperiênciasdeeducaçãodoMovimento de Educação de Base (MEB), os trabalhos desenvolvidos pelos movimentos de cultura popular e pelos centros populares de cultura e a elaboração, pelo Ministério da Educação e 
Cultura, do Programa Nacional de Alfabetização.

Trata-se do que Brandão (2002, p. 145) chama de "amplo, difuso e intenso movimento" conduzido por educadores pedagogos e não pedagogos de formação. Propostas ainda frágeis, em um sentido de "experimentação". Trabalho pedagógico quase nunca formalmente escolar, realizado no campo e na cidade, envolvendo grêmios estudantis, agências da Igreja Católica, sindicatos e o que seriam considerados os movimentos populares. Como principal idealizador, Paulo Freire, e os movimentos de cultura popular seriam sua "agência prioritária de criação de ideias e de realização de experiências" (BRANDÃO, 2002, p. 145). As propostas e iniciativas concretas do que se chamou de educação popular foram germinadas por "uma ampla frente polissêmica de ideias e de ações, nunca tão política ou ideologicamente centralizada" (BRANDÃO, 2002, p. 145).

Importante salientar, conforme Bezerra e Brandão (1987), que, entre os anos de 1959 e 1963, boa parte dessas ações tinha ou o patrocínio ou o respaldo do governo (tanto federal, como estadual e municipal). Em alguns casos, elas estavam nas estruturas do Estado, como a Campanha Nacional de Alfabetização, que não se realizou por conta do golpe militar de 1964 (BRANDÃO, 2002). Essas ações eram realizadas como que em caráter de urgência:

[...] as instituições não se contentavam com a criação de núcleos de participação limitada [...], mas tendiam a uma atuação de massa, de cunho sensibilizatório e mobilizatório. (BEZERRA; BRANDÃO, 1987, p. 24).

Segundo esses autores, o objetivo era o de chegar às coletividades por mediações com ampla capacidade de mobilização.

O MEB foi um projeto da Igreja Católica para alfabetização de jovens e adultos, tendo à frente, entre outros, Álvaro Vieira Pinto, que propunha discutir o tipo de homem que se deveria formar para o tipo de desenvolvimento, nacional e autônomo, que se desejava (DIAS; ARAÚJO, 2002). O MEB buscou a interface entre educação de base e educação popular. Como explica Wanderley (2010, p. 29), "para superar os valores importados", o caminho foi o da animação popular, realizada por meiodo rádio, de caravanas populares de cultura, das publicações diversas, das manifestações da arte e da cultura do povo. Buscava-se, também, entrelaçar as noções de cultura e consciência histórica.

Nesta linha, o MEB e outros movimentos de cultura popular - como a Ação Popular - que chegaram ao teatro, ao cinema, à música e ao rádio, marcam esse momento da educação popular no Brasil. Os diversos meios de mobilização popular (que iam da alfabetização de adultos aos festivais de cultura, entre outros) eram também instrumentos de conscientização, politização e organização do povo. Sua validade estava na possibilidade que apresentavam para a libertação do povo de suas alienações (FÁVERO, 1983, p. 24).

Também é dessa época a formação dos Centros Populares de Cultura (CPC), por meio da atuação da União Nacional dos Estudantes (UNE). Criados em 1961, esses centros se espalharam rapidamente pelo país.

No campo, os camponeses se organizavam principalmente por meio do MEB e das Ligas Camponesas. Já na década de 1950, as Ligas procuravam mobilizar e organizar os camponeses, por meio de reivindicações de seus direitos, como a posse da terra, o voto e a autonomia para se organizarem. Esse processo de reivindicação tornou-se mais "revolucionário" no início da década de 1960 (KADT, 2007).

Este período é o que marca as características fundamentais da educação popular, suas fontes e seus desafios. Entre as fontes, pode-se citar o pensamento de Paulo Freire, a Teologia da Libertação, as Teorias do Desenvolvimento e da Dependência, o referencial marxista e as experiências revolucionárias de outras partes do mundo, em 
especial da América Latina (PALUDO, 2009).

É no início da década de 1960 que Paulo Freire faz a experiência de seu método de alfabetização de adultos, no bojo do Movimento de Cultura Popular (MCP). Freire integrou o MCP e essa passagem, como informa Streck (2009, p. 65), a partir de entrevista do próprio Freire, abriu-lhe "uma larga possibilidade de aprendizado e gestação de uma teoria pedagógica", citando também a influência de teóricos como John Dewey e Jean Piaget.

Freire aplicou com sucesso o seu método de alfabetização de adultos em Angicos, cidade do Rio Grande do Norte, durante o governo de Miguel Arraes, em 1963. Por isso, foi convidado para aplicá-lo também a nível nacional. Mas o projeto, assim como todo o projeto de educação popular, foi "abortado" com o Golpe Militar de 1964. Exilado no Chile, em 1967, o educador escreveu, a partir de suas experiências no Brasil e no Chile e diante de um mundo em transformação, aquela que seria sua obra mais importante: Pedagogia do Oprimido.

Com o período da ditadura militar, os movimentos populares que deram origem à educação popular se desarticulam no início para, depois, reapresentarem-se com outras propostas, novos sujeitos e novas formas de agir. No entanto, esse primeiro período lança as bases e forma as lideranças para continuar o processo de se repensar a sociedade e buscar sua transformação a partir e com os oprimidos.

No período que se seguiu ao golpe de 1964 até 1989, a educação popular é fortemente associada aos movimentos sociais e suas lutas pelos direitos políticos, civis, sociais e econômicos. Segundo Arroyo (2003, p. 31), esses movimentos sociais atuaram como "pedagogos no aprendizado dos direitos sociais".

Brandão (2002, p. 150) afirma que entre os anos de 1970 e 1980, "ao longo dos governos militares e da 'abertura política', houve toda uma intensa associação entre a educação popular e os movimentos populares". Nessa fase, o movimento operário, o novo sindicalismo, com formas diversas de articulação, buscou se aproximar dos movimentos que lutavam por direitos, ainda que de forma dispersa (ARROYO, 2003). É desse período também o advento de várias modalidades de pesquisa participante, vinculadas às ideias e práticas da educação popular (BRANDÃO, 2002). Foram criadas redes de teóricos e praticantes, realizados congressos e encontros, inclusive internacionais, publicados livros e artigos e produzidos trabalhos acadêmicos de mestrado e doutorado sobre a pesquisa participante. Destacam-se, também, na década de 1970, o trabalho realizado pelas Comunidades Eclesiais de Base (CEBs), formadas por grupos de jovens, de noivos ou casais e clubes de mães, entre outros, e os núcleos de trabalhadores vinculados às pastorais, como a operária e a da terra. Ainda nessa década, bem como no início da seguinte, os grupos de oposição sindical, sindicatos e associações educacionais e culturais não podiam realizar atividades políticas e eram vigiados. O trabalho educativo passou a ser visto também como resistência e contestação da ordem institucional, mas, no entanto, sem o discurso político explícito (MANFREDI, 2009).

Os centros de assessoria à educação popular tornaram-se os lugares públicos onde se reelaboraram novas sínteses do método dialógico de Paulo Freire (MANFREDI, 2009). Os centros de assessoria à educação popular transformaram-se nas ONGs da década de 1980, politizadas e articuladas a partidos, sindicatos e alas da Igreja progressista (GOHN, 2005, p. 85).

No Brasil, nos anos de 1970 e 1980, as ONGs cidadãs e militantes estiveram por detrás da maioria dos movimentos sociais populares urbanos que delinearam um cenário de participação na sociedade civil, trazendo para a cena política novos personagens, contribuindo decisivamente para a queda do regime militar e para a transição democrática no país. As ONGs contribuíram para a reconstrução do conceito de 
"sociedade civil", termo originário doliberalismo, que adquire novos significados, menos centrados na questão do indivíduo e mais direcionados para os direitos de grupos (GOHN, 2005). Para Semeraro (2009, p. 107),

[...] a práxis libertadora e as crescentes pressões de movimentos populares juntamente com outras forças sociopolíticas concorreram para minar e derrubar os regimes militares no Brasil e na América.

O autor aponta para uma mudança nas concepções político-pedagógicas desses movimentos, afirmando que, no início dos anos de 1980, "encerrava-se um ciclo histórico e se esgotavam também muitas concepções e práticas político-pedagógicas originadas em seu seio" (SEMERARO, 2009, p. 107). Citando Freire, Semeraro destaca a passagem dos processos de conscientização e de libertação para uma prática da transformação da realidade:

[...] as ações de resistência, os círculos de cultura, "as comunidades de base", as práticas educacionais e as associações populares de bairro surgidas durante a ditadura haviam cumprido o seu papel de fermentação e de reivindicações. (SEMERARO, 2009, p. 107).

Os conceitos gramscianos são recebidos na América e no Brasil, mudando tanto a linguagem de pessoas dos setores acadêmico, político e dos movimentos sociais quanto as formas de organização e ação, no final dos anos de 1970 e início dos anos de 1980. Sociedade civil, Estado ampliado, escola unitária, intelectual orgânico e bloco histórico, entre outros conceitos, começam a popularizar-se, tanto no mundo acadêmico, como no político e nos movimentos populares. Paulo Freire é um dos que "percebe esse fenômeno e se sintoniza com ele" (SEMERARO, 2009, p. 110).

Nas palavras de Streck (2009, p. 68), o que interessava não era mais o confronto direto com o Estado, mas a "ocupação de espaços na sociedade civil que garantissem a construção de um projeto de cunho popular".

É também nesta época (1980) que se cria o Partido dos Trabalhadores (PT), do qual Paulo Freire é um dos membros fundadores, e que passa a representar as expectativas cultivadas ao longo de duas décadas de silenciamento dos movimentos, muitas vezes na clandestinidade. Ainda, neste período, formamse importantes lideranças, tanto no âmbito dos sindicatos como no das CEBs (STRECK, 2009).

Outras instituições são organizadas pelos trabalhadores do campo e da cidade. Entre algumas delas, o Movimento dos Trabalhadores Rurais Sem Terra (MST), iniciado em 1980, que assumiu a matriz pedagógica freireana na formação de seus quadros e lideranças. A Central Única dos Trabalhadores (CUT), criada em 1983, constitui seu Departamento Nacional de Formação, também adotando a pedagogia freireana como uma das suas matrizes fundantes (MANFREDI, 2009, p. 143).

No entanto, nem todas as experiências de organização e ação políticas resultaram no esperado projeto de democracia popular, almejado pelos movimentos sociais populares das décadas de 1970 e 1980. De acordo com Semeraro (2009, p. 114),

[...] as preocupações eleitorais, a corrida para os cargos executivos, a "governabilidade" e a burocratização dos partidos acabaram por marginalizar muitos movimentos sociais e esvaziar suas dinâmicas revolucionárias.

A década de 1990 chega repleta de mudanças na economia e no mundo do trabalho, afetados, por um lado, pela hegemonia do projeto neoliberal e, por outro, pelas novas tecnologias de comunicação. Com a abertura política, em meados da década de 1980, há novas configurações no campo político e partidário. A sociedade dita 
"civil" também se reinventa, surgindo o que se denomina de novos movimentos sociais.

Na percepção de Ledezma e Bazán (2009, p. 137), marcado por um novo projeto de homogeneização cultural e de unipolarização, o neoliberalismo

[...] tem definido uma nova conjuntura na qual os movimentos sociais e os processos de libertação e autonomia social, cultural e econômica foram deslocados da centralidade sociopolítica.

Segundo os autores, nessa conjuntura, o espaço e a prática dos movimentos se metamorfosearam ou evaporaram. Para os proponentes, há uma dificuldade dos movimentos, neste novo contexto, de construir um "cenário alternativo" e de

[...] estruturar discursos e estratégias que articulem educação com sociedade, cultura, economia e política em sua perspectiva de empoderamento real da sociedade civil. (LEDEZMA; BAZÁN, 2009, p. 138).

Apesar destes limites, vários movimentos, com raízes nos períodos anteriores aqui abordados, marcaram presença na cena política, construindo, de acordo com Wanderley (2010, p. 68-69),

[...] os mecanismos de fortalecimento dos próprios movimentos e lutando por reformas políticas que eliminassem os ressaibos ditatoriais e avançassem numa efetiva democratização, ora buscando articulações em redes e fóruns.

No campo da educação, surgem novos conceitos e novas formas de se organizar e agir, assim como novos movimentos sociais, neste novo modo de ser e se fazer movimento social. De acordo com Brandão (2002), os movimentos populares, sendo organizações dinâmicas e militantes da sociedade civil, perdem dois atributos radicais do passado. Primeiro, deixam de ser, com exclusividade, movimentos de classes trabalhadoras. Segundo, não são mais movimentos de ação revolucionária direta via enfrentamentos radicais com o sistema de poder.

Outra característica do campo social dos movimentos no Brasil (mas também na América Latina e em todo o mundo) é

[...] a crescente criação de "frentes de aliados", ao lado de uma contínua criação e extensão de redes de intercomunicação e de teias de mútuo compromisso entre unidades e uniões de movimentos sociais. (BRANDÃO, 2002, p. 271).

Paludo (2009, p. 49) denomina de Campo Popular a "articulação das diversas organizações do povo político, com seus aliados". Esses últimos seriam algumas ONGs, alguns setores das Igrejas, partidos, personalidades e intelectuais comprometidos com as causas populares. A autora ainda salienta que, apesar das contradições e da diversidade de matizes, esse campo é plural e tem como referencial a transformação das sociedades. Aliás, sobre as ONGs, é preciso distinguir organizações que colaboram para a criação de "espaços e formatos de participação e de relações sociais" $(\mathrm{GOHN}, 1997$, p. 304), das que se tornaram pequenas empresas do "terceiro setor", em busca de recursos públicos e não públicos para sua sobrevivência, sem o compromisso de uma atuação crítica junto às comunidades onde se instalam, reforçando a lógica capitalista. Entretanto, são estas últimas ONGs as que têm prevalecido dentro do crescente mercado social que se fortalece neste início de século XXI, levando as demais ONGs e entidades comprometidas com a educação popular a se adaptar aos ditames do mercado social e das regulamentações do Estado. 


\section{Perspectivas}

A diversidade sempre foi uma característica do movimento de educação popular no Brasil. No período que se iniciou em 1990 e nos tempos atuais, não é diferente. As ONGs se consolidam, com diferentes métodos e finalidades de trabalho, mas várias ainda com o ideal da educação popular e da transformação da realidade. Sua sustentabilidade financeira vinha, basicamente, das agências internacionais de cooperação. No entanto, a partir dos anos 2000, essa realidade se transforma, com as agências colocando seus recursos em outras regiões do planeta, como a África ea Índia. Muitas organizações ou fecham as portas ou se adaptam às novas formas de "captação" e "mobilização" de recursos, como os convênios em parceria com os setores governamentais, fundações e instituições nacionais e internacionais. Essa mudança não foi somente de fonte, mas também de ação: para captar recursos, as ONGs tiveram que adaptar seu trabalho às demandas das financiadoras, o que nem sempre equivale às demandas das comunidades e grupos "atendidos". Mesmo assim, é possível distinguir alguns movimentos e ações de educação popular, dentro da diversidade e das dificuldades dos trabalhos realizados nessa fase.

Oliveira (2006, p. 11) informa que na década de 1990, as propostas de educação popular não se limitaram às

experiências de educação política das massas, ou mesmo, à alfabetização de jovens e adultos e ensino supletivo para frações das camadas populares, realizados predominantemente nos espaços não-escolares da sociedade civil.

Segundo a autora, houve experiências de escolarização regular e extraescolares de preparação para a escolarização de nível superior. Ressalta, nesse período, o Movimento Sem Terra e a Central Única dos Trabalhadores, bem como, no âmbito do Estado, as experiências de educação popular desenvolvidas nos municípios e estados com os governos ditos democráticos e populares. Dá destaque também para o Movimento de Pré-Vestibulares Populares que surgem na metade da década de 1980, com forte crescimento entre os anos de 1994 e 1999 (cerca de 57\%), e que "contam com o envolvimento dos sujeitos coletivos como a Igreja Católica, os movimentos negro, estudantil, sindical e comunitário" (OLIVEIRA, 2006, p. 14).

É na década de 1990 que a educação de adultos recebe novo nome: Educação de Jovens e Adultos (EJA). Ainda nesta década, surge o Movimento de Educação Popular e Saúde, que reúne agentes comunitários, profissionais da área de saúde e pesquisadores. Como frente de luta, o tema da saúde foi constante nas décadas de 1970 e 1980, mas, como movimento unindo as duas temáticas, seu nascimento se dá a partir do Simpósio Inter-Americano de Educação para a Saúde, no Rio de Janeiro (FANTIN, 2000).

Em 2003, com a eleição do candidato Lula para presidente da República, o tema da educação popular como política pública volta a ser colocado na pauta dos movimentos populares que atuam nessa área. Seja pelo financiamento público de atividades de formação pedagógica dos movimentos, seja pela organização das atividades de participação popular (como as conferências de políticas públicas), o debate sobre Educação Popular e Estado retorna. A criação do Setor de Mobilização Social, que permitiu a articulação da Rede de Educação Cidadã (RECID), é outro diferencial desse momento político. A experiência mais fortemente ilustrativa de períodos anteriores, da relação "política pública e educação popular" foi a gestão de Paulo Freire como Secretário de Educação de São Paulo, no governo de Luíza Erundina, em 1989 (RECID, 2009b). Além dessa experiência, pode ser lembrado o governo de Celso Daniel (19972000), no município de Santo André (SP), que 
contribuiu para a formulação da concepção de gestão pública orientada por princípios da educação popular. Outra experiência significativa nesse campo é a do Orçamento Participativo, especialmente a de Porto Alegre (RS), implementado na gestão 1999-2002, que envolveu gestão democrática e o controle social.

Em 2003, a ampla participação dos movimentos populares na eleição de Lula teria se refletido em ações dentro dos Ministérios. Alguns desses ministérios buscaram desenvolver políticas públicas e, com o tempo, ensaiaram políticas intersetoriais (RECID, 2009b). Ainda em 2003, algumas tentativas foram lançadas, destaque para a que resultou na articulação da Rede de Educação Cidadã (RECID), ligada inicialmente ao Programa Fome Zero (RECID, 2009b).

As tentativas, realizações e dificuldades da RECID, investigadas em pesquisa de um dos autores deste artigo, ilustram os próprios dilemas da educação popular no início do século XXI. Por sob o discurso da transformação social e da educação popular mobilizadora, os agentes do que seriam os atuais movimentos sociais tantas vezes comportam-se como representantes de uma ONG em busca de mais recursos, para o fortalecimento de sua entidade neste mercado social que hegemoniza o campo das práticas socioeducativas.

\section{Considerações Finais}

Tendo como referência a caminhada histórica da Educação Popular no Brasil (perpassando também pela América Latina), buscou-se, aqui, explicitar a práxis, ou as práxis, político-pedagógicas da educação popular. Percebe-se que, apesar da mudança de paradigmas, principalmente, a partir da década de 1990, os princípios fundantes dessa práxis continuam tendo validade, e é o que caracteriza o seu conjunto. Esses princípios poderiam, resumidamente, ser listados como pedagógicos, políticos e organizativos. No primeiro, encontramos o diálogo como caminho fundamental; no segundo, a transformação das realidades de desumanização, como objetivo de "luta"; e no terceiro, a diversidade que não exclui, pelo contrário, busca articular-se de várias formas em torno dos objetivos comuns.

Os caminhos históricos da educação popular nos ensinam que seu nascimento deuse no interior mesmo de uma interessante confluência entre Estado e organizações sociais, como Igreja e universidades, nos tempos do populismo no Brasil e na América Latina, que forçou o Estado, no início dos anos 1960, a apoiar financeiramente projetos de educação e cultura popular com forte teor crítico e mobilizador de populações. Depois, a educação popular viveu e reviveu apesar das ameaças e da repressão dos governos militares. Foi um ator fundamental no processo de redemocratização do país. Ela vai penar e perder muito de seu sentido original no final do século XX e início do século $X X I$, em parte porque alguns dos seus objetivos foram realmente atingidos com o fim da ditadura e a conquista de importantes direitos sociais e espaços de participação popular. Mas, principalmente, pela ressignificação das práticas socioeducativas operada pelo mercado social, pelas novas diretrizes do Estado e pela ortodoxia criada pela pedagogia social. Aqueles princípios da práxis da educação popular e os ensinamentos deixados pela história e elencados nesta análise são pontos de partida fundamentais para quem deseja contestar as atuais feições do campo das práticas socioeducativas, bem como propor heterodoxias contra a ortodoxia que vai se tornando dominante. Informam e revelam construções de outros tempos ao educador insatisfeito com os cerceamentos que tais práticas socioeducativas têm recebido do Estado e do mercado social, em troca de recursos financeiros, de reconhecimento e legitimidade. 


\section{Referências}

ARROYO, M. Paulo Freire e o projeto popular para o Brasil. In: SOUZA, A. I. (Org.). Paulo Freire: vida e obra. 3. ed. São Paulo: Expressão Popular, 2005.

BEZERRA, A.; BRANDÃO, C. R. (Org.). A questão política da educação popular. 7. ed. São Paulo: Brasililense, 1987.

BRANDÃO, C. R. A educação popular na escola cidadã. Petrópolis, RJ: Vozes, 2002.

BRANDÃO, C. R. Apresentação. In: BEZERRA, A.; BRANDÃO, C. R. (Org.). A questão política da educação popular. 7. ed. São Paulo: Brasililense, 1987.

CALIMAN, G. Pedagogia social: seu potencial crítico e transformador. Revista de Ciências da Educação, São Paulo, ano XII, n. 23, p. 341-370, 2. sem. 2010.

DIAS, S. S.; ARAÚJO, J. C. S. Fundamentos da teoria educacional em Vieira Pinto. SBHE, 2002. Disponível em: <http://www.sbhe.org.br/ novo/congressos/cbhe2/pdfs/Tema4/0414.pdf.> Acesso em: 28 ago. 2011.

FANTIN, M. Educação popular e saúde: conquistas e desafios no contexto brasileiro. Caderno de debate Educação popular e saúde: diálogos com a vida. Florianópolis, SC: 2000. Disponível em: <http://www.gices-sc.org/Edu.pdf>. Acesso em: 28 ago. 2011.

FREIRE, P. Extensão ou comunicação? São Paulo: Paz e Terra, 2010.

FREIRE, P. Pedagogia da autonomia. 37. ed. São Paulo: Paz e Terra, 2008.

FREIRE, P. Pedagogia do oprimido. 48. ed. Rio de Janeiro: Paz e Terra, 2009.

GADOTTI, M. Saber aprender: um olhar sobre Paulo Freire e as perspectivas atuais da educação. 2000. Disponível em: <acervo.paulofreire.org/xmlui/bitstream/handle/7891/2999/FPF_ PTPF_01_0366.pdf>. Acesso em: 20 fev. 2013.

GARCIA, V. A. A educação não formal como acontecimento. 2009, 456 f. Tese (Doutorado em Educação), Universidade Estadual de Campinas, Campinas-SP, 2009.

GARCIA, V. A. Realismo da exclusão social. Revista de Ciências da Educação, São Paulo, ano VII, n. 12, p. 113-132, 1. sem. 2005.

GARRIDO, N. de C.; SILVA, O. M. da; EVANGELISTA, F. (Org.). Pedagogia social: educação e trabalho na perspectiva da pedagogia social. São Paulo: Expressão \& Arte, 2011.

GOHN, M. da G. Educação não formal e cultura política: impactos sobre o associativismo do terceiro setor. 3. ed. São Paulo: Cortez, 2005. (Coleção questões da nossa época).

GOHN, M. da G. Teorias dos movimentos sociais: paradigmas clássicos e contemporâneos. São Paulo: Loyola, 1997.

GRACIANI, M. S. S. Pedagogia social de rua: análise e sistematização de uma experiência vivida. 4. ed. São Paulo: Cortez, 2001. 
KADT, E. de. Católicos radicais no Brasil. Brasília: UNESCO: MEC, 2007. (Coleção Educação Para Todos).

KONDER, L. O futuro da filosofia da práxis: o pensamento de Marx no século XXI. Rio de Janeiro: Paz e Terra, 1992.

LEDEZMA, N. A.; BAZÁN, L. A. R. Políticas públicas educativas com participação social: um meio para reconstruir concepções e práticas desde a educação popular. In: PONTUAL, P.; IRELAND, T. Educação popular na América Latina: diálogos e perspectivas. Brasília, DF: Ministério da Educação: UNESCO, 2009. (Coleção Educação Para Todos).

MANFREDI, S. M. Contribuições freirianas para a organização dos movimentos sindical e popular no Brasil. In: MAFRA, J. et al. (Org.). Globalização, educação e movimentos sociais: 40 anos da Pedagogia do Oprimido. São Paulo: Instituto Paulo Freire: Esfera, 2009.

OLIVEIRA, E. S. Movimentos sociais e educação popular no Brasil urbano-industrial. 2006. Disponível em: < http://www.anped.org.br/reunioes /29ra/trabalhos/trabalho/GT03-2268--Int. pdf $>$. Acesso em: 28 ago. 2011.

PALUDO, C. Educação popular: dialogando com redes latino-americanas (2000-2003). In: PONTUAL, P.; IRELAND, T. Educação popular na América Latina: diálogos e perspectivas. Brasília, DF: Ministério da Educação: UNESCO, 2009. (Coleção Educação Para Todos).

PARK, M. B.; FERNANDES, R. S. (Org.). Educação não formal: contextos, percursos e sujeitos. Campinas: Centro de Memória da Unicamp, 2005.

RECID (Rede de Educação Cidadã). Educação popular como política pública. 2009. Disponível em: <http://www.recid.org.br/ comunicoteca/item/35-ep-politicapublica.html>. Acesso em: 28 ago. 2011.

SCHNORR, G. M. Pedagogia do oprimido. In: SOUZA, A. I. (Org.). Paulo Freire: vida e obra. 3. ed. São Paulo: Expressão Popular, 2005.

SILVA, R. da (Org.). III Congresso de pedagogia social. Revista de Ciências da Educação, São Paulo, ano XII, n. 22, p. 167-448, 1 sem. 2010.

SIMSON, O. R. de M. V. PARK, M. B.; FERNANDES, R. S. (Org.). Educação não formal: cenários da criação. Campinas: Editora da Unicamp, 2001.

STRECK, D. Uma pedagogia em movimento: os movimentos sociais na obra de Paulo Freire. In: MAFRA, J. et al. (Org.). Globalização, educação e movimentos sociais: 40 anos da Pedagogia do Oprimido. São Paulo: Instituto Paulo Freire: Esfera, 2009.

Submetido em 21 de abril de 2013.

Aprovado em 28 de maio de 2013. 